\title{
Alfabetização financeira de estudantes universitários a partir das dimensões atitude financeira, comportamento financeiro e conhecimento financeiro
}

\author{
Nadia Mar Bogoni" \\ Maurício Leite** \\ Fábio Roberto Barão**** \\ Mariza de Almeida ${ }^{* * * * *}$ \\ Nelson Hein ${ }^{* * * * * *}$
}

\begin{abstract}
Resumo
É notória a importância que os temas alfabetização financeira e educação financeira vêm ganhando na vida das pessoas. Nesse sentido, o objetivo deste artigo é caracterizar o perfil dos estudantes universitários de uma universidade localizada na Região Norte do estado do Rio Grande do Sul, a partir das dimensões atitude financeira, comportamento financeiro e conhecimento financeiro. Para tanto, a pesquisa caracterizou-se como um estudo de caso, em que 194 alunos participaram respondendo um questionário on-line. Os dados obtidos foram analisados com utilização de estatística descritiva e multivariada (análise fatorial). Os resultados mostram que os estudantes participantes da pesquisa têm um nível satisfatório de alfabetização financeira, considerando as dimensões atitude, comportamento e conhecimento financeiros. Porém, 57\% estão insatisfeitos com sua situação financeira. Percebe-se também que os alunos respondentes demonstram ter preocupação com seu futuro financeiro, priorizando manter uma poupança e pagar contas em dia. Além disso, nota-se que os respondentes apresentam um satisfatório conhecimento financeiro sobre taxa de juros, retorno financeiro, risco, ativos financeiros e inflação.
\end{abstract}

Palavras-chave: Alfabetização financeira. Análise fatorial. Educação financeira.

* Mestre em Ciências Contábeis pela Universidade Regional de Blumenau e doutoranda em Ciências Contábeis e Administração na mesma instituição. Professora na Universidade de Passo Fundo. E-mail: nbogoni@upf.br

** Mestre em Ciências Contábeis pela Universidade Regional de Blumenau e doutorando em Ciências Contábeis e Administração na mesma instituição. E-mail: mauricio.leite@gmail.com

**** Mestre em Engenharia pela Universidade de Passo Fundo. Professor na mesma instituição. E-mail: fbarao@upf.br

***** Economista pela Universidade de Passo Fundo e mestranda em Economia e Desenvolvimento na Universidade Federal de Santa Maria. E-mail: marizaalmeida12@gmail.com

****** Professor no Programa de Pós-Graduação em Ciências Contábeis da Universidade Regional de Blumenau. Pós-doutoramento no Instituto Nacional de Matemática Pura e Aplicada e na Anderson School of Management da Universidade do Novo México. E-mail: hein@furb.br

http://dx.doi.org/10.5335/rtee.v24i50.8962

Submissão: 16/03/2018. Aceite: 04/06/2018. 


\section{Introdução}

Temas como alfabetização financeira e educação financeira estão cada vez mais presentes na vida das pessoas, e isso se deve ao crescente desenvolvimento dos mercados financeiros e às mudanças demográficas, econômicas, políticas e sociais a que a sociedade está exposta. Todas essas mudanças afetam, consideravelmente, a vida das pessoas, independentemente de classe social ou nível de renda.

Embora esses termos sejam, frequentemente, tratados como sinônimos, eles são conceitos diferentes, pois alfabetização financeira vai além de educação financeira, cujo foco principal é o conhecimento. A alfabetização financeira envolve a atitude e o comportamento financeiros dos indivíduos (POTRICH; VIEIRA; KIRCH, 2015).

Para um indivíduo ser alfabetizado financeiramente, ele deve ter capacidade e confiança para usar seu conhecimento financeiro, a fim de tomar decisões financeiras prudentes, ou seja, de aplicar o conhecimento de forma apropriada. Assim, a alfabetização financeira tem duas dimensões: o entendimento e a utilização do conhecimento. Na dimensão do entendimento, os indivíduos apresentam conhecimento financeiro pessoal ou educação financeira. Por sua vez, na utilização do conhecimento, os indivíduos aplicam tais conhecimentos na gestão das finanças pessoais (HUSTON, 2010).

Com o intuito de sanar problemas, a Organisation for Economic Co-Operation and Development (OECD) (2013), por meio da International Network on Financial Education (Infe), desenvolveu um instrumento de pesquisa para mensurar a alfabetização financeira nos mais diversos países. A abordagem compreende, simultaneamente, a atitude financeira, o comportamento financeiro e o conhecimento financeiro.

No Brasil, o tema alfabetização financeira ganhou maior importância a partir de 2010, quando foi instituída a Estratégia Nacional de Educação Financeira (Enef), cujas finalidades são promover a educação financeira e previdenciária e contribuir para o fortalecimento da cidadania, da eficiência do sistema financeiro nacional e da tomada de decisões conscientes por parte dos consumidores (BRASIL, 2011).

Nos estudos voltados para a alfabetização financeira entre jovens, Lusardi, Mitchell e Curto (2010) buscaram identificar o conhecimento sobre educação financeira entre jovens americanos. Os autores constataram baixo grau de instrução financeira entre os jovens pesquisados: menos de um terço possuía conhecimentos básicos sobre taxas de juros, inflação e diversidade de riscos. O baixo nível de instrução financeira foi relacionado com características sociodemográficas e condições

Teoria e Evidência Econômica - a. 24, n. 50, p. 187-206, jan./jun. 2018 
de renda das famílias. Cull e Whitton (2011) realizaram um estudo com estudantes universitários da Austrália das áreas de Gestão, Artes e Saúde. Dos resultado, os autores concluíram que os conhecimentos sobre taxas bancárias e impostos estão relacionados com o nível de renda, e os conhecimentos acerca dos planos de aposentadoria aumentam conforme a idade vai aumentando.

Já Atkinson e Messy (2012), a partir da metodologia proposta pela OCDE/ Infe, pesquisaram a criação de indicadores de alfabetização financeira baseados em comportamento financeiro, conhecimento financeiro e atitudes financeiras, para 14 países membros da OCDE. Os autores concluíram que a maioria dos indivíduos possui grau muito básico de conhecimentos financeiros, com pouca compreensão de conceitos financeiros do dia a dia. Também evidenciaram excesso de confiança dos respondentes e grau mais baixo de alfabetização financeira em mulheres do que em homens em quase todos os países pesquisados.

No contexto brasileiro, entre pesquisas que tratam da alfabetização financeira entre jovens, encontram-se os estudos de Potrich, Vieira e Ceretta (2013), Potrich, Vieira e Kirch $(2014,2015)$ e Milan (2015), que estudaram o nível de alfabetização financeira de estudantes universitários, baseados em atitude, comportamento e conhecimento financeiros.

Nos estudos mencionados, observa-se a necessidade de evoluir na investigação do nível de conhecimento sobre os conceitos que envolvem a alfabetização financeira. Há uma desconexão marcante nas definições conceituais de alfabetização financeira, por isso seria interessante desenvolver medidas mais conectadas. Em especial, neste estudo, são utilizadas as medidas desenvolvidas a partir do modelo proposto pela OCDE (2013), que define alfabetização financeira em três dimensões: atitude financeira; comportamento financeiro; e conhecimento financeiro; sendo adaptado do estudo realizado pelos pesquisadores Potrich, Vieira e Kirch (2014).

A estimação de um modelo de alfabetização financeira dessa natureza é de suma importância, uma vez que os governantes estão interessados em encontrar abordagens dinâmicas e capazes de melhorar o nível de alfabetização financeira da população. Essa busca pela alfabetização está ligada a criação ou aperfeiçoamento de estratégias nacionais que proporcionem oportunidades de aprendizagem para diferentes níveis educacionais (ATKINSON; MESSY, 2012).

Diante do exposto e considerando a importância da alfabetização financeira, tanto no contexto econômico quanto no social, tem-se por objetivo, a partir das dimensões atitude financeira, comportamento financeiro e conhecimento financeiro, caracterizar o perfil dos estudantes de uma universidade localizada na Região Norte do estado do Rio Grande do Sul. 
Assim, a pesquisa trata de um tema que vem apresentando crescimento tanto em economias desenvolvidas como em economias em desenvolvimento. De acordo com Orton (2007), a alfabetização financeira pode ainda ser entendida como uma ferramenta promotora de coesão social. Ou seja, ela é importante tanto para a segurança dos indivíduos como para a segurança das nações. Além disso, essa alfabetização é uma forma de evitar desigualdades e assegurar que todos participem da criação e da distribuição da riqueza.

\section{Referencial teórico}

$\mathrm{Na}$ presente seção, é feita uma breve abordagem sobre alfabetização financeira e sua importância para a formação de cidadãos conscientes com relação a seus gastos, endividamentos e investimentos. Também é dado enfoque à educação financeira, pois alfabetização e educação financeiras têm um papel preponderante na formação e na educação dos jovens.

\section{Alfabetização financeira: conceitos e dimensões}

A alfabetização financeira é definida como a combinação de consciência, conhecimentos, habilidades, atitudes e comportamentos necessários para a tomada de decisões financeiras sólidas. Ela consiste no conhecimento de temas relacionados ao mercado monetário, econômico ou financeiro, bem como às decisões que os indivíduos têm a capacidade de tomar, a partir das informações adquiridas. Também é conhecida como a habilidade de ler, analisar, gerir e comunicar sobre a condição financeira pessoal e a forma como esta afeta o bem-estar material dos indivíduos (ORGANIZATION FOR ECONOMIC CO-OPERATION AND DEVELOPMENT, 2005; ORTON, 2007).

A alfabetização financeira acontece em sala de aula, por meio de materiais de informativos, sites educativos e jogos interativos, além de aconselhamento individual. Essas formas de informar os indivíduos sobre educação financeira visam a torná-lo experiente, educado e informado sobre questões de gestão de dinheiro e bens, serviços bancários, investimentos, crédito, seguros e impostos, bem como a possibilitar a compreensão dos conceitos básicos relativos ao valor do dinheiro no tempo. Assim, a alfabetização financeira só é eficaz se permitir que os consumidores, dada a sua limitação de recursos, possam tomar decisões eficazes ao longo de suas vidas (WILLIS, 2008). 
Para Lusardi e Mitchell (2011), embora seja importante avaliar a alfabetização financeira das pessoas, na prática é difícil descobrir a forma como as pessoas processam as informações financeiras e tomam suas decisões baseadas nos conhecimentos adquiridos. Segundo os autores, isso ocorre pelo fato de que a alfabetização financeira abrange vários conceitos, compreendendo a consciência financeira, os conhecimentos financeiros, as habilidades financeiras e a capacidade financeira, o que dificulta na captação das informações de uma só vez.

Apesar das diversas formas como o conceito de alfabetização financeira é abordado, a maioria delas contempla o conhecimento, a habilidade para aplicar os conceitos adquiridos, a atitude para gerenciar as finanças pessoais, as aptidões para tomar decisões apropriadas e a confiança para planejar as necessidades financeiras futuras (REMUND, 2010). Para melhor entendimento dos conceitos e dimensões da alfabetização financeira, no Quadro 1 apresentam-se alguns, conforme Potrich, Vieira e Kirch (2015).

Quadro 1 - Principais conceitos e dimensões da alfabetização financeira

\begin{tabular}{|c|c|c|}
\hline Conceitos de alfabetização financeira & Dimensões & Autores \\
\hline $\begin{array}{l}\text { O conhecimento financeiro e a aplicação desse } \\
\text { conhecimento com autoconfiança na tomada de } \\
\text { decisões financeiras }\end{array}$ & $\begin{array}{l}\text { Conhecimento financeiro e } \\
\text { aplicação do conhecimento }\end{array}$ & Huston (2010) \\
\hline $\begin{array}{l}\text { A capacidade de usar o conhecimento e as habili- } \\
\text { dades adquiridas para uma gestão melhor }\end{array}$ & $\begin{array}{l}\text { Conhecimento financeiro e ha- } \\
\text { bilidades }\end{array}$ & $\begin{array}{l}\text { Hung, Parker e Yoong } \\
(2009)\end{array}$ \\
\hline $\begin{array}{l}\text { A capacidade de compreender a informação fi- } \\
\text { nanceira e tomar decisões eficazes, utilizando } \\
\text { essa informação }\end{array}$ & Compreensão e decisão & CLIFF et al. (2012) \\
\hline $\begin{array}{l}\text { A influência do conhecimento financeiro sobre o } \\
\text { comportamento mediado pelas atitudes financeiras }\end{array}$ & $\begin{array}{l}\text { Conhecimento, comportamen- } \\
\text { to e atitudes }\end{array}$ & $\begin{array}{l}\text { Norvilitis e MacLean } \\
(2010)\end{array}$ \\
\hline $\begin{array}{l}\text { A escolha de inúmeras alternativas para o estabe- } \\
\text { lecimento dos objetivos financeiros }\end{array}$ & Escolha eficaz & Criddle (2006) \\
\hline A tomada de decisões financeiras informadas & Decisões financeiras & Remund (2010) \\
\hline $\begin{array}{l}\text { O capital humano mais específico, medido por } \\
\text { meio de questões de conhecimentos financeiros }\end{array}$ & Conhecimento financeiro & Cliff e Sharpe (2009) \\
\hline $\begin{array}{l}\text { O conjunto de perguntas para medir conceitos } \\
\text { financeiros básicos, como capitalização de juros, } \\
\text { inflação e diversificação de risco }\end{array}$ & Conhecimento financeiro & Lusardi e Mitchell (2011) \\
\hline $\begin{array}{l}\text { A alfabetização financeira em três dimensões: o } \\
\text { conhecimento financeiro, o comportamento finan- } \\
\text { ceiro e a atitude financeira }\end{array}$ & $\begin{array}{l}\text { Conhecimento financeiro, } \\
\text { comportamento financeiro e } \\
\text { atitude financeira }\end{array}$ & $\begin{array}{l}\text { Atkinson e Messy (2012); } \\
\text { Organisation for Economic } \\
\text { Co-Operation and } \\
\text { Development (2013) }\end{array}$ \\
\hline
\end{tabular}

Fonte: elaborado com base em Potrich, Vieira e Kirch (2015). 
A partir do Quadro 1, percebe-se que diversos autores conceituam a alfabetização financeira como sinônima de conhecimento financeiro ou educação financeira, pois a mensuram apenas com esse constructo. No entanto, nota-se que alguns pesquisadores a conceituam de forma ampla, mensurando-a em outros aspectos, como o comportamento financeiro, a atitude financeira, as experiências financeiras, entre outros. A falta de um conjunto padronizado de medidas de alfabetização financeira consistente não impediu o surgimento de um número significativo de estudos (POTRICH; VIEIRA; KIRCH, 2015).

Diante do exposto, é evidente os benefícios que o acesso à alfabetização financeira bem como à educação financeira tem para o gerenciamento das finanças pessoais. Dessa forma, deve-se atentar, cada vez mais, para a saúde financeira das pessoas e procurar desenvolver instrumentos que facilitem à sociedade o acesso a esse tipo de informação. Devido à importância do tema, bem como à sua efetiva relação com a educação financeira, é oportuno buscar cada vez mais participantes e promover o conhecimento sobre o assunto.

\section{Educação financeira e sua importância para as finanças pessoais}

O conceito de educação financeira é expresso pela OCDE (2005) como um processo pelo qual os consumidores financeiros ou investidores melhoram a sua compreensão sobre os conceitos e produtos financeiros. Por meio da informação, da instrução e de aconselhamentos claros e objetivos, os indivíduos tendem a desenvolver habilidades e confiança, para tomar consciência de oportunidades e riscos financeiros, fazer escolhas informadas, saber em que meios buscar ajuda e tomar outras medidas eficazes para melhorar a sua proteção e o seu bem-estar financeiro.

Conforme destacado, diversos organismos internacionais têm reconhecido a importância da educação financeira como mecanismo de inclusão social. De acordo com Mundy (2009), a educação financeira tem como objetivo dar apoio para que as pessoas possam gerir bem o seu dinheiro ao longo das suas vidas. Para o autor, há um consenso geral de que o propósito da educação financeira emerge como alternativa de política pública para incrementar os conhecimentos financeiros da população vulnerável, minimizando, de alguma forma, o risco a que está exposta.

Para Greenspan (2005), a educação financeira é caracterizada como um o conjunto de informações que auxilia as pessoas a gerenciar sua renda, seu dinheiro, seus gastos e empréstimos monetários, sua poupança e seus investimentos a curto e longo prazos. A promoção da educação financeira habilita os indivíduos a vencer

Teoria e Evidência Econômica - a. 24, n. 50, p. 187-206, jan./jun. 2018 
suas relutâncias e inabilidades, de modo que tirem total vantagem dos avanços tecnológicos e de novos produtos no setor financeiro e possam aumentar suas oportunidades econômicas. A qualificação dos indivíduos torna-os melhores consumidores e melhores compradores. Esse processo efetivamente aumenta o poder de compra real e provê maiores oportunidades para consumir mais, poupar ou investir.

A importância da qualificação dos indivíduos também é apresentada por Bernheim, Garrett e Maki (2001) e Bernheim e Garrett (2003). Os estudos demonstram que pessoas alfabetizadas financeiramente têm melhores índices de poupança e planos para aposentadoria, o que traz melhores perspectivas para $o$ futuro e para resolução de problemas financeiros.

Pessoas bem informadas financeiramente têm maior capacidade de gerência e maior compreensão da importância do dinheiro e de sua utilização. O conhecimento de educação financeira é pertinente para qualquer indivíduo que queira buscar melhores formas de usar o seu dinheiro. A educação financeira é imprescindível tanto na vida diária dos indivíduos como na organização de empresas e do governo (NORMAN, 2010).

Segundo Grifoni e Messy (2012), tanto nas economias em desenvolvimento como nas desenvolvidas, a consciência da importância da educação financeira levou ao desenvolvimento de um número crescente de estratégias nacionais, a fim de implantá-la e disseminá-la. Para os autores, conhecimentos, competências, habilidades e conceitos econômicos são necessários para as atividades econômicas mais triviais empreendidas, recorrentemente, pelos agentes que interagem em economias de mercado.

Opletalová (2015) afirma que a necessidade de disseminar o conhecimento sobre educação financeira está na elevação constante que o índice de endividamentos pessoal e familiar vem apresentando. Para a autora, a única maneira possível de eliminar ou diminuir esse fenômeno é pela conscientização financeira das pessoas a partir da educação, seja em sala de aula, seja em espaços públicos, com parcerias entre instituições privadas, organismos nacionais e internacionais e a sociedade como um todo.

Devido à importância do tema, parece oportuno cada vez mais divulgar e disseminar a educação financeira. Nesse processo, é elementar e necessário a participação de escolas, empresas, do governo, instituições financeiras, universidades, organizações não governamentais, entre outros. 


\section{Metodologia}

Com o propósito de responder as questões elaboradas neste estudo, a pesquisa tem características de cunho descritivo, com abordagens qualitativa e quantitativa para a coleta dos dados. Por meio de estudo de caso, buscaram-se entender e caracterizar os estudantes universitários de uma universidade da Região Norte do estado do Rio Grande do Sul.

Caracterizada como estudo de caso, a pesquisa envolveu um total de 194 alunos; estes responderam a um questionário elaborado no Google Docs e disponibilizado on-line durante o período de maio, junho e julho de 2017. Após a coleta dos dados, foi feita a análise dos resultados por estatística descritiva, para a caracterização socioeconômica. Para analisar atitudes e comportamento financeiros, utilizou-se a estatística de análise fatorial (AF), que visa a sintetizar as informações de um grande número de variáveis em um número muito menor de fatores (HAIR et al., 2009.)

Com a redução do número de variáveis, a parcela explicada pelos fatores comuns recebe o nome de comunalidade, que pode variar de 0 a 1 , sendo que valores próximos de 0 são os fatores comuns que não explicam a variância, e valores próximos de 1 indicam que todas as variâncias são explicadas pelos fatores comuns (MAROCO, 2007; HAIR et al., 2009). Para Hair et al. (2009), o pesquisador deve decidir qual carga fatorial vale a pena ser considerada. A regra geral considera que cargas maiores que 0,3 atingem o nível mínimo, cargas de 0,4 são consideradas mais importantes, e cargas superiores a 0,5 são estatisticamente significativas. Neste estudo, são consideradas as cargas fatoriais acima de 0,5 (MAROCO, 2007).

Cabe destacar que o conhecimento financeiro não passou pelo processo de validação para $\mathrm{AF}$, pois esse constructo foi construído a partir de variáveis nominais (resposta certa ou resposta errada). Nesse sentido, optou-se pela estatística descritiva, a fim de analisar cada questão específica. Assim, a caracterização da alfabetização dos estudantes universitários para as três dimensões é feita de questões distribuídas de acordo com o exposto no Quadro 2. 


\section{Quadro 2 - Distribuição da pesquisa survey efetuada com os participantes de oficinas de educação financeira em suas escolas}

\begin{tabular}{|c|c|c|c|}
\hline $\begin{array}{l}\text { a) Caracterização } \\
\text { socioeconômica }\end{array}$ & $\begin{array}{l}\text { 1. Qual é a sua idade? } \\
\text { 2. Que curso você frequenta? } \\
\text { 3. Com que gênero você se identifica? }\end{array}$ & $\begin{array}{l}\text { 4. Qual é a sua renda bruta men- } \\
\text { sal? } \\
\text { 5. Qual é a sua ocupação? } \\
\text { 6. Você é financeiramente inde- } \\
\text { pendente de seus pais e/ou } \\
\text { familiares? }\end{array}$ & $\begin{array}{l}\text { 7. Em geral, você está satisfeito } \\
\text { com a sua situação financei- } \\
\text { ra? } \\
\text { 8. Em um mês normal, quão di- } \\
\text { fícil é para você cumprir com } \\
\text { seus compromissos financei- } \\
\text { ros? }\end{array}$ \\
\hline $\begin{array}{l}\text { b) Atitude financeira } \\
\text { (10 questões em } \\
\text { escala Likert de } 5 \\
\text { pontos, sendo: } 1= \\
\text { discordo totalmente; } \\
2 \text { = discordo; } 3 \\
=\text { indiferente; } 4 \\
\text { = concordo; } 5= \\
\text { concordo totalmente.) }\end{array}$ & $\begin{array}{l}\text { 1. Acho importante definir metas para o } \\
\text { futuro. } \\
\text { 2. Não me preocupo com o futuro, vivo } \\
\text { o presente. } \\
\text { 3. Poupar é impossível para mim. } \\
\text { 4. Eu gosto de comprar coisas. Tenho sa- } \\
\text { tisfação pessoal em comprar. }\end{array}$ & $\begin{array}{l}\text { 5. É difícil construir, mensalmente, } \\
\text { um planejamento de gastos. } \\
\text { 6. Só gasto meu dinheiro com coi- } \\
\text { sas que são importantes para } \\
\text { mim. } \\
\text { 7. No geral, estou satisfeito com a } \\
\text { minha situação financeira. }\end{array}$ & $\begin{array}{l}\text { 8. Considero mais satisfatório } \\
\text { gastar meu dinheiro do que } \\
\text { poupar para o futuro. } \\
\text { 9. Dinheiro é feito para gastar. } \\
\text { 10. É importante controlar as } \\
\text { despesas mensais. }\end{array}$ \\
\hline $\begin{array}{l}\text { c) Comportamento } \\
\text { financeiro } \\
\text { (14 questões em } \\
\text { escala Likert de } 5 \\
\text { pontos, sendo: } 1 \text { = } \\
\text { nunca; } 2 \text { = quase } \\
\text { nunca; } 3 \text { = às vezes; } \\
4 \text { = quase sempre; } 5 \\
\text { = sempre,) }\end{array}$ & $\begin{array}{l}\text { 1. Anoto e controlo meus gastos pesso- } \\
\text { ais (planilhas de receita e despesas; blo- } \\
\text { cos; aplicativo no celular; etc.). } \\
\text { 2. Comparo preços ao fazer uma com- } \\
\text { pra. } \\
\text { 3. Tenho um plano para gastos. } \\
\text { 4. Consigo identificar os juros embutidos } \\
\text { numa compra a prazo. } \\
\text { 5. Pago minhas contas em dia. }\end{array}$ & $\begin{array}{l}\text { 6. Guardo parte da minha renda } \\
\text { todo mês. } \\
\text { 7. Gasto meu dinheiro antes de } \\
\text { recebê-lo. } \\
\text { 8. Dinheiro é feito para gastar. } \\
\text { 9. Frequentemente peço dinhei- } \\
\text { ro emprestado para familiares e } \\
\text { amigos. } \\
\text { 10. Analiso minhas contas antes } \\
\text { de fazer uma despesa de longo } \\
\text { prazo. } \\
\text { 11. Evito comprar por impulso. }\end{array}$ & $\begin{array}{l}\text { 12. Pago minhas faturas do car- } \\
\text { tão de crédito em dia para evitar } \\
\text { cobrança de juros. } \\
\text { 13. Eu me preocupo em poupar } \\
\text { para o futuro. } \\
\text { 14. Costumo contrair emprésti- } \\
\text { mos bancários ou outros tipos } \\
\text { de financiamentos. }\end{array}$ \\
\hline $\begin{array}{l}\text { d) Conhecimento } \\
\text { financeiro } \\
\text { (questões sobre } \\
\text { juros, inflação, } \\
\text { valor do dinheiro } \\
\text { no tempo, } \\
\text { investimentos, etc., } \\
\text { com duas opções de } \\
\text { resposta e apenas } \\
\text { uma correta.) }\end{array}$ & $\begin{array}{l}\text { 1. Suponha que você tenha } \mathrm{R} \$ 100,00 \\
\text { em uma conta poupança a uma taxa de } \\
\text { juros de } 10 \% \text { ao ano. Depois de } 5 \text { anos, } \\
\text { qual o valor que você terá na poupança? } \\
\text { Considere que não tenha sido deposita- } \\
\text { do nem retirado dinheiro. } \\
\text { 2. Imagine que você herde HOJE } \\
\mathrm{R} \$ 10.000,00 \text { e seu irmão herde } \mathrm{R} \$ \\
10.000,00 \text { daqui } 3 \text { anos. Quem ficará } \\
\text { mais rico, considerando essa herança? } \\
\text { 3. Imagine que a taxa de juros incidente } \\
\text { sobre sua conta poupança seja de } 6 \% \text { ao } \\
\text { ano, e a taxa de inflação seja de } 10 \% \text { ao } \\
\text { ano. Após } 1 \text { ano, quanto você será capaz } \\
\text { de comprar com o dinheiro dessa conta? } \\
\text { Considere que não tenha sido deposita- } \\
\text { do nem retirado dinheiro durante esse } \\
\text { período. }\end{array}$ & $\begin{array}{l}\text { 4. Suponha que no ano de } 2018 \\
\text { sua renda dobrará, e os preços de } \\
\text { todos os bens também dobrarão. } \\
\text { Em } 2018 \text {, quanto você será capaz } \\
\text { de comprar com a sua renda? } \\
\text { 5. Considerando um longo período } \\
\text { de tempo (p. ex., } 10 \text { anos), qual } \\
\text { ativo, normalmente, você conside- } \\
\text { ra que oferece maior retorno? } \\
\text { 6. Quando um investidor distribui } \\
\text { seu investimento entre diferentes } \\
\text { ativos, qual é o risco de perder } \\
\text { dinheiro? } \\
\text { 7. Um empréstimo com duração } \\
\text { de } 15 \text { anos normalmente exige } \\
\text { pagamentos mensais maiores do } \\
\text { que um empréstimo de } 30 \text { anos, } \\
\text { mas o total de juros pagos ao final } \\
\text { do empréstimo é menor. Qual é } \\
\text { sua opção de empréstimo? }\end{array}$ & $\begin{array}{l}\text { 8. Suponha que você viu o } \\
\text { mesmo televisor em duas lojas } \\
\text { diferentes pelo preço inicial de } \\
\mathrm{R} \$ 1.000 .00 \text {. A loja A oferece um } \\
\text { desconto de } \mathrm{R} \$ 150,00 \text {, enquan- } \\
\text { to a loja B oferece um desconto } \\
\text { de } 10 \% \text {. Qual é a melhor alter- } \\
\text { nativa? } \\
\text { 9. Imagine que cinco amigos } \\
\text { recebem uma doação de } \mathrm{R} \$ \\
1.000,00 \text { e precisam dividir o } \\
\text { dinheiro igualmente entre eles. } \\
\text { Quanto cada um vai obter? } \\
\mathbf{1 0 .} \text { Quando a inflação aumenta, } \\
\text { o custo de vida sobe? } \\
\mathbf{1 1 .} \text { Um investimento com alto re- } \\
\text { torno também será de alto risco? }\end{array}$ \\
\hline
\end{tabular}

Fonte: elaboração dos autores.

Teoria e Evidência Econômica - a. 24, n. 50, p. 187-206, jan./jun. 2018 


\section{Análise dos resultados}

\section{Análise do perfil dos respondentes}

O questionário foi respondido por 194 alunos de uma universidade da Região Norte do Rio Grande do Sul, sendo que $60 \%$ pertencem ao gênero feminino e têm idade média de 24 anos. Os estudantes participantes da pesquisa são dos cursos de Economia (19\%), Administração (38\%), Ciências Contábeis (35\%), Comércio Exterior (4\%), Gestão Comercial (2\%), Agronegócios (3\%) e Recursos Humanos (1\%).

No que tange à renda, $64 \%$ dos alunos apresentam renda bruta de 1 a 3 salários mínimos, sendo que $75 \%$ têm emprego assalariado, e $53 \%$ são financeiramente independentes de seus pais. Observa-se que $57 \%$ dos respondentes estão insatisfeitos com sua situação financeira, $45 \%$ consideram fácil cumprir com os compromissos financeiros, $30 \%$, difícil, e $13 \%$, indiferente.

\section{Análise da atitude, do comportamento e do conhecimento financeiros}

Após a definição do perfil dos respondentes, passou-se à construção dos fatores relativos à atitude financeira e ao comportamento financeiro, por meio da realização da análise fatorial exploratória (AFE). Quanto ao método de rotação, foi utilizado o procedimento Varimax. Para verificar a adequação da utilização da AFE, aplicaram-se os testes de Kaiser-Meyer-Olkin (KMO) e de esfericidade de Bartlett. $\mathrm{O}$ KMO mede a adequação dos dados, de modo que os valores devem ser maiores que 0,6 , indicando que a realização da análise fatorial é satisfatória. Já o teste de esfericidade de Bartlett avalia a hipótese de as variáveis não serem correlacionadas na população, ou seja, de não haver correlação perfeita entre as variáveis (HAIR et al., 2009).

\section{Atitude financeira}

Para a análise da atitude financeira, realizaram-se os testes de KMO e Bartlett, cujos resultados encontram-se na Tabela 1. O KMO para atitude financeira é de 0,664, considerado aceitável e de significância de 0,000 , indicando a adequação da análise fatorial. 
Tabela 1 - Testes de KMO e Bartlett para atitude financeira

\begin{tabular}{l|lr}
\hline Medida Kaiser-Meyer-Olkin de adequação & &, 664 \\
\hline \multirow{4}{*}{ de amostragem } & & 262,423 \\
\hline & $\begin{array}{l}\text { Qui-quadrado } \\
\text { aproximação }\end{array}$ & 45 \\
\cline { 2 - 3 } & diferença &, 000 \\
\cline { 2 - 3 } & significância & 20 \\
\hline
\end{tabular}

Fonte: elaboração dos autores.

Na Tabela 2 apresenta-se a variância total explicada, em que se observa que quatro fatores explicam $61,68 \%$ da variância.

Tabela 2 - Variância total explicada

\begin{tabular}{l|c|c|c}
\hline \multicolumn{1}{c|}{ Fatores } & $\begin{array}{c}\text { Valores próprios iniciais } \\
\text { (total) }\end{array}$ & Variância (\%) & Cumulativo (\%) \\
\hline Está preocupado com o futuro. & 2,517 & 25,17 & 25,17 \\
Não está preocupado com o futuro. & 1,454 & 14,54 & 39,71 \\
Não tem capacidade de planejamento. & 1,179 & 11,79 & 51,50 \\
Apresenta satisfação em consumir. & 1,018 & 10,18 & 61,68 \\
\hline
\end{tabular}

Fonte: elaboração dos autores.

Em seguida, analisaram-se as comunalidades: quanto mais próximas de 1, maior é a explicação dos fatores. Por meio da análise dos componentes de atitudes financeiras (Tabela 3), observa-se que oito componentes explicam os fatores (grupos): alunos que estão preocupados com o futuro (3 componentes), alunos que não estão preocupados com o futuro (2 componentes), alunos que não conseguem fazer planejamento financeiro ( 2 componentes) e alunos que sentem prazer em consumir (1 componente). 
Tabela 3 - Componentes atitudes financeiras

\begin{tabular}{l|c|c|c|c}
\hline \multirow{1}{*}{ Componentes } & \multicolumn{3}{c}{ Fatores } \\
\cline { 2 - 5 } & $\begin{array}{c}\text { Está } \\
\text { preocupado } \\
\text { com o futuro }\end{array}$ & $\begin{array}{c}\text { Não está } \\
\text { preocupado } \\
\text { com o futuro }\end{array}$ & $\begin{array}{c}\text { Não tem } \\
\text { capacidade de } \\
\text { planejamento }\end{array}$ & $\begin{array}{c}\text { Apresenta } \\
\text { satisfação em } \\
\text { consumir }\end{array}$ \\
\hline $\begin{array}{l}\text { Considero importante controlar as } \\
\text { despesas mensais. }\end{array}$ & 0,789 & & \\
$\begin{array}{l}\text { Considero importante definir metas para } \\
\text { o futuro. }\end{array}$ & 0,727 & & \\
$\begin{array}{l}\text { A forma que administro meu dinheiro vai } \\
\text { afetar meu futuro. }\end{array}$ & 0,718 & 0,810 & \\
$\begin{array}{l}\text { Considero mais satisfatório gastar meu } \\
\text { dinheiro do que poupar para o futuro. }\end{array}$ & & 0,765 & \\
$\begin{array}{l}\text { Dinheiro é feito para gastar. } \\
\text { Considero difícil construir, mensalmente, } \\
\text { um planejamento de gastos. }\end{array}$ & & & 0,797 & \\
$\begin{array}{l}\text { Poupar é impossível para mim. } \\
\text { Eu gosto de comprar coisas. Isso me faz } \\
\text { sentir bem. }\end{array}$ & & & 0,737 & \\
\hline
\end{tabular}

Fonte: elaboração dos autores.

Nota: método de extração - análise do componente principal; método de rotação - varimax.

Dos dados calculados, observa-se que o fator 1 (estar preocupado com o futuro) representa $25,17 \%$ da variância e é composto por três das principais variáveis relacionadas, as quais remetem a um comportamento em que os entrevistados demonstram uma certa preocupação em gerenciar, planejar e buscar sustentabilidade financeira para o futuro. As cargas fatoriais deste fator foram compostas pelas seguintes variáveis: importância de controlar as despesas mensais, importância de definir metas para o futuro e a forma como a administração dos recursos afeta o futuro. Relevantes, também, são os dados das cargas fatoriais dos fatores 2,3 e 4, cujos componentes remetem para a satisfação que o hábito de consumir traz, além do fato de considerar impossível planejar e poupar.

\section{Comportamento financeiro}

Para a análise do comportamento financeiro, realizaram-se, inicialmente, os testes de KMO e Bartlett, cujos resultados encontram-se na Tabela 4. O KMO para atitude financeira é de 0,762 , considerado aceitável e de significância de 0,000, indicando a adequação da análise fatorial. 
Tabela 4 - Testes de KMO e Bartlett para comportamento financeiro

\begin{tabular}{l|lr}
$\begin{array}{l}\text { Medida Kaiser-Meyer-Olkin de adequação de } \\
\text { amostragem }\end{array}$ & &, 762 \\
\multirow{3}{*}{ Teste de esfericidade de Bartlett } & Qui-quadrado aproximação & 646,955 \\
\cline { 2 - 3 } & diferença & 91 \\
\cline { 2 - 3 } & significância &, 000 \\
\hline
\end{tabular}

Fonte: elaboração dos autores.

Na Tabela 5, apresenta-se a variância total explicada, em que se observa que cinco fatores explicam $63,33 \%$ da variância.

Tabela 5 - Variância total explicada

\begin{tabular}{l|c|c|c}
\hline \multicolumn{1}{c|}{ Fatores } & $\begin{array}{c}\text { Valores próprios } \\
\text { iniciais (total) }\end{array}$ & Variância (\%) & Cumulativo (\%) \\
\hline Financeiramente controlado & 3,82 & 27,35 & 27,35 \\
Orçamento organizado & 1,70 & 12,17 & 39,52 \\
Consumidor & 1,21 & 8,68 & 48,19 \\
Consome sem planejamento & 1,07 & 7,63 & 55,87 \\
Contrai dívidas & 1,04 & 7,47 & 63,33 \\
\hline
\end{tabular}

Fonte: elaboração dos autores.

Em seguida, analisaram-se as comunalidades: quanto mais próximas de 1, maior é a explicação dos fatores. Assim, dos componentes de comportamento financeiro (Tabela 6), observa-se que os 12 componentes analisados explicam os cinco fatores (grupos): alunos que são financeiramente controlados (5 componentes); alunos que possuem um controle orçamentário mensal (2 componentes); alunos que são ávidos por consumo, que entendem que o dinheiro é feito para gastar (2 componentes); alunos que são cautelosos nos gastos, mas têm renda mensal insuficiente (2 componentes); e, por fim, alunos que contraem dívidas frequentemente (1 componente). 
Tabela 6 - Componentes comportamentos financeiros

\begin{tabular}{|c|c|c|c|c|c|}
\hline \multirow[b]{2}{*}{ Componentes } & \multicolumn{5}{|c|}{ FATORES } \\
\hline & $\begin{array}{l}\text { Controle } \\
\text { financeiro }\end{array}$ & $\begin{array}{l}\text { Orçamento } \\
\text { organizado }\end{array}$ & Consumidor & $\begin{array}{l}\text { Consumo } \\
\text { sem } \\
\text { planeja- } \\
\text { mento }\end{array}$ & $\begin{array}{l}\text { Contrai dívi- } \\
\text { das }\end{array}$ \\
\hline Pago minhas contas em dia. & 0,824 & & & & \\
\hline $\begin{array}{l}\text { Guardo parte da minha renda todo } \\
\text { mês. }\end{array}$ & 0,689 & & & & \\
\hline $\begin{array}{l}\text { Pago minhas faturas do cartão de cré- } \\
\text { dito em dia, para evitar cobrança de } \\
\text { juros. }\end{array}$ & 0,666 & & & & \\
\hline $\begin{array}{l}\text { Eu me preocupo em poupar para o fu- } \\
\text { turo. }\end{array}$ & 0,629 & & & & \\
\hline $\begin{array}{l}\text { Analiso minhas contas antes de fazer } \\
\text { uma despesa de longo prazo. }\end{array}$ & 0,546 & & & & \\
\hline $\begin{array}{l}\text { Anoto e controlo meus gastos pessoais } \\
\text { (planilhas de receita e despesas; blo- } \\
\text { cos; aplicativo no celular; etc.). }\end{array}$ & & 0,866 & & & \\
\hline Tenho um plano de gastos. & & 0,812 & & & \\
\hline Dinheiro é feito para gastar. & & & 0,839 & & \\
\hline Gasto meu dinheiro antes de recebê-lo. & & & 0,591 & & \\
\hline $\begin{array}{l}\text { Frequentemente peço dinheiro empres- } \\
\text { tado para familiares e amigos. }\end{array}$ & & & & 0,656 & \\
\hline Evito comprar por impulso. & & & & 0,625 & \\
\hline $\begin{array}{l}\text { Costumo contrair empréstimos bancá- } \\
\text { rios ou outros tipos de financiamentos. }\end{array}$ & & & & & 0,829 \\
\hline
\end{tabular}

Fonte: elaboração dos autores.

Nota: método de extração: análise do componente principal; método de rotação: varimax.

Conforme os dados calculados, observa-se que o fator 1 (controle financeiro) representa $27,35 \%$ da variância e é composto por quatro das principais variáveis relacionadas, as quais remetem a um comportamento em que os entrevistados demonstram uma preocupação em manter o pagamento das contas em dia e poupar e são consumidores conscientes, analisando seu dinheiro antes de gastar. As cargas fatoriais deste fator foram compostas pelas componentes: pago minhas contas em dia, guardo parte da minha renda todos mês, tenho preocupação em poupar para o futuro e analiso minhas contas antes de fazer uma despesa de longo prazo. Destacam-se, também, as cargas fatoriais para os fatores relacionados aos controles de gastos mensais. Neles, aparecem os ávidos por consumo; os que consomem, mas têm renda mensal insuficiente, buscando socorro financeiro com familiares e 
amigos. E, por fim, os que contraem dívidas, ou seja, costumam contrair empréstimos bancários e outros tipos de financiamentos.

\section{Conhecimento financeiro}

Para avaliar o nível de conhecimento financeiro dos universitários, buscou-se construir um índice a partir das respostas às questões de múltipla escolha, conforme explicitado na metodologia. A Tabela 7 apresenta o percentual de respostas corretas e incorretas e das perguntas que os entrevistados não souberam responder sobre conhecimento financeiro. Esses percentuais foram obtidos com base no número de estudantes respondentes.

Tabela 7 - Percentual de respostas corretas e incorretas e das perguntas que os entrevistados não souberam responder sobre conhecimento financeiro

\begin{tabular}{|c|c|c|c|}
\hline Variáveis & $\begin{array}{l}\text { Percentual de } \\
\text { respostas corretas }\end{array}$ & $\begin{array}{c}\text { Percentual de } \\
\text { respostas incorretas }\end{array}$ & $\begin{array}{l}\text { Percentual das } \\
\text { perguntas não } \\
\text { respondidas }\end{array}$ \\
\hline $\begin{array}{l}\text { Suponha que você tenha } R \$ 100,00 \text { em uma conta poupança } \\
\text { a uma taxa de juros de } 10 \% \text { ao ano. Depois de } 5 \text { anos, qual o } \\
\text { valor que você terá na poupança? Considere que não tenha sido } \\
\text { depositado nem retirado dinheiro. }\end{array}$ & $65 \%$ & $32 \%$ & $3 \%$ \\
\hline $\begin{array}{l}\text { Imagine que você herde HOJE R\$ } 10.000,00 \text { e seu irmão herde } \\
\mathrm{R} \$ 10.000,00 \text { daqui } 3 \text { anos. Quem ficará mais rico, considerando } \\
\text { essa herança? }\end{array}$ & $51 \%$ & $37 \%$ & $12 \%$ \\
\hline $\begin{array}{l}\text { Imagine que a taxa de juros incidente sobre sua conta poupança } \\
\text { seja de } 6 \% \text { ao ano e a taxa de inflação seja de } 10 \% \text { ao ano. Após } \\
1 \text { ano, quanto você será capaz de comprar com o dinheiro dessa } \\
\text { conta? Considere que não tenha sido depositado nem retirado } \\
\text { dinheiro durante esse período. }\end{array}$ & $71 \%$ & $16 \%$ & $13 \%$ \\
\hline $\begin{array}{l}\text { Suponha que no ano de } 2018 \text { sua renda dobrará e os preços de } \\
\text { todos os bens também dobrarão. Em 2018, quanto você será } \\
\text { capaz de comprar com a sua renda? }\end{array}$ & $70 \%$ & $28 \%$ & $2 \%$ \\
\hline $\begin{array}{l}\text { Considerando um longo período de tempo (p. ex., } 10 \text { anos), qual } \\
\text { ativo, normalmente, você considera que oferece maior retorno? }\end{array}$ & $31 \%$ & $60 \%$ & $9 \%$ \\
\hline $\begin{array}{l}\text { Quando um investidor distribui seu investimento entre diferentes } \\
\text { ativos, qual é o risco de perder dinheiro? }\end{array}$ & $72 \%$ & $20 \%$ & $8 \%$ \\
\hline $\begin{array}{l}\text { Um empréstimo com duração de } 15 \text { anos normalmente exige } \\
\text { pagamentos mensais maiores do que um empréstimo de } 30 \\
\text { anos, mas o total de juros pagos ao final do empréstimo é } \\
\text { menor. Qual é sua opção de empréstimo? }\end{array}$ & $75 \%$ & $18 \%$ & $7 \%$ \\
\hline $\begin{array}{l}\text { Suponha que você viu o mesmo televisor em duas lojas } \\
\text { diferentes pelo preço inicial de } \mathrm{R} \$ 1.000 .00 \text {. A loja A oferece um } \\
\text { desconto de } \mathrm{R} \$ 150,00 \text {, enquanto a loja B oferece um desconto } \\
\text { de } 10 \% \text {. Qual é a melhor alternativa? }\end{array}$ & $93 \%$ & $4 \%$ & $3 \%$ \\
\hline $\begin{array}{l}\text { Imagine que cinco amigos recebem uma doação de } R \$ 1.000,00 \\
\text { e precisam dividir o dinheiro igualmente entre eles. Quanto cada } \\
\text { um vai obter? }\end{array}$ & $98 \%$ & $0 \%$ & $2 \%$ \\
\hline Quando a inflação aumenta, o custo de vida sobe? & $95 \%$ & $4 \%$ & $2 \%$ \\
\hline Um investimento com alto retorno também será de alto risco? & $93 \%$ & $4 \%$ & $3 \%$ \\
\hline
\end{tabular}

Fonte: elaboração dos autores. 
O conjunto de questões apresentadas na Tabela 7 sobre conhecimento financeiro teve por objetivo analisar o entendimento dos universitários em aspectos como taxa de juros, retorno financeiro, risco, ativos financeiros (ações, títulos públicos, etc.), diversificação de investimento, valor do dinheiro no tempo e inflação. Das questões, nove apresentaram um bom nível de acertos (acima de 60\%), referentes a inflação, taxa de juros, ativos financeiros, entre outros. A questão relativa ao valor do dinheiro no tempo obteve um percentual de acertos de 51\%; enquanto a questão sobre retorno financeiro (valor do dinheiro no tempo) foi respondida corretamente por apenas $31 \%$ dos alunos.

De acordo com as respostas fornecidas, verifica-se que há um nível satisfatório de compreensão dos estudantes em relação a assuntos que estão diariamente disponíveis, como em noticiários ou em situações de compra de mercadorias, e até mesmo a assuntos abordados em sala de aula relativos a inflação, juros, valor do dinheiro no tempo, investimentos, entre outros. Conforme a Tabela 7, em média, $74 \%$ dos estudantes acertaram as questões, $20 \%$ não acertaram, e 6\% não souberam responder nenhuma das 11 questões presentes no questionário.

\section{Considerações finais}

A partir do objetivo proposto neste artigo e após a análise dos dados, conclui-se que os alunos em sua maioria são indivíduos assalariados e financeiramente independentes dos pais ou familiares. Porém, observa-se que os respondentes estão insatisfeitos com sua situação financeira.

A caracterização do perfil a partir das dimensões abordas é a seguinte:

a) atitude financeira: destaca-se a evidente preocupação com o futuro, explicada pelas cargas fatoriais importância de controlar as despesas mensais, importância de definir metas para o futuro e a forma como a administração dos recursos afeta o futuro. Demonstra-se, assim, uma preocupação dos estudantes com relação ao controle financeiro e, consequentemente, a propensão de ter um futuro com estabilidade financeira;

b) comportamento financeiro: destaca-se também a preocupação dos estudantes com relação ao futuro financeiro, explicada pelas cargas fatoriais pagar as contas em dia, ter uma poupança (guardar parte da renda todos mês), preocupar-se em poupar para o futuro, analisar as contas antes de fazer uma despesa de longo prazo e controlar os gastos mensais. Dessa forma, percebe-se que os participantes têm consciência da importância de gerenciar suas finanças pessoais e garantir uma estabilidade financeira no futuro. 
Por fim, foi analisado o conhecimento financeiro dos estudantes quanto a aspectos como taxa de juros, retorno financeiro, risco, ativos financeiros (ações, títulos públicos, etc.), diversificação de investimento, valor do dinheiro no tempo e inflação. Houve um bom nível de acertos em nove questões, referentes a inflação, taxa de juros, ativos financeiros, entre outros. Em média, mais da maioria dos estudantes acertou as questões.

Nesse sentido, pode-se avaliar que os estudantes universitários que participaram da pesquisa têm um nível satisfatório de alfabetização financeira, considerando as três dimensões: atitude, comportamento e conhecimento financeiros. A parte dos respondentes que acha relativamente fácil controlar e gerenciar os gastos mensais demonstra ter preocupação com o futuro financeiro, priorizando manter hábitos de poupança e pagamento das contas em dia. Corroborando com os resultados encontrados, Lusardi e Mitchell (2011) afirmam que, à medida que aumenta o nível de educação financeira, os indivíduos passam a ter um planejamento maior tanto de gastos quanto de poupança e estão propensos a levar uma vida financeira saudável. 


\title{
Financial literacy of university students from the dimensions financial attitude, financial behavior and financial knowledge
}

\begin{abstract}
It is notorious the importance that the subjects financial literacy, as well as financial education, has been gaining strength in people's lives. In this sense, the objective of this article is to characterize the profile of the university students of a University located in the North Region of the state of Rio Grande do Sul, from the dimensions of financial attitude, financial behavior and financial knowledge. To do so, the study constituted a case study, in which 194 students participated by responding to an online questionnaire. Data were analyzed using descriptive and multivariate statistics (factorial analysis). As a result, the students participating in the research have a satisfactory level of financial literacy, considering the three dimensions: financial attitude, behavior and knowledge. However, $57 \%$ are dissatisfied with their financial situation. It is also noticed that the students respondents demonstrate to have a concern with the financial future, prioritizing to maintain habits of saving and payment of the current accounts. In addition, the respondents present a satisfactory financial knowledge about interest rate, financial return, risk, financial assets and inflation.
\end{abstract}

Keywords: Financial literacy. Factor analysis. Financial education.

\section{Alfabetización financiera de estudiantes universitarios a partir de las dimensiones actitud financiera, comportamiento financiero y conocimiento financiero}

\section{Resumen}

Es notoria la importancia que los temas alfabetización financiera y educación financiera, vienen ganando en la vida de las personas. En este sentido, el objetivo de este artículo es caracterizar el perfil de los estudiantes universitarios de una Universidad ubicada en la Región Norte del estado de Rio Grande do Sul, a partir de las dimensiones de actitud financiera, comportamiento financiero y conocimiento financiero. Para ello, la investigación se constituyó en un estudio de caso, en que 194 alumnos participaron respondiendo a un cuestionario online. Los datos obtenidos fueron analizados con utilización de estadística descriptiva y multivariada (análisis factorial). Como resultado, se tiene que los estudiantes, participantes en la investigación, tienen un nivel satisfactorio de alfabetización financiera, considerando las tres dimensiones: actitud, comportamiento y conocimiento financiero. Sin embargo, el $57 \%$ está insatisfechos con su situación financiera. Se percibe también, que los alumnos respondedores demuestran tener una preocupación con el futuro financiero, priorizando mantener hábitos de ahorro y pago de las cuentas al día. Además, se observa que los encuestados presentan un satisfactorio conocimiento financiero sobre tasa de interés, retorno financiero, riesgo, activos financieros e inflación.

Palabras clave: Alfabetización financiera. Análisis factorial. Educación financiera. 


\section{Referências}

ATKINSON, A.; MESSY, F. Measuring financial literacy: results of the OECD/International Network on Financial Education (INFE) Pilot Study. OECD Working Papers on Finance, Insurance and Private Pensions, Paris, OECD Publishing, n. 15, Apr. 2012.

BERNHEIM, B. D.; GARRETT, D. M.; MAKI, D. M. Education and saving: the long-term effects of high school financial curriculum mandates. Journal of Public Economics, [s.1.], v. 80, n. 3, p. 435-465, Jun. 2001.

BERNHEIM, B. D.; GARRETT, D. M. The effects of financial education in the workplace: evidence from a survey of households. Journal of Public Economics, [s.l.], v. 87, n. 7, p. 14871519, ago. 2003.

BRASIL. Estratégia Nacional de Educação Financeira - Plano Diretor da ENEF. 2011. Disponível em: <http://www.vidaedinheiro.gov.br/>. Acesso: 1ํo maio 2017.

CLIFF, A. R.; SHARPE, D. L. Effect of Personal Financial Knowledge on College Students' Credit Card Behavior. Journal of Financial Counseling and Planning (JFCP), University of Rhode Island, USA, v. 20, n. 1, p. 25-43, 2009.

CLIFF, A. et al. The demand for financial professionals' advice: the role of financial knowledge, satisfaction, and confidence. Financial Services Review, Stetson University School of Business, USA, v. 21, p. 291-305, 2012.

CRIDDLE, E. Financial literacy: goals and values, not just numbers. Alliance Editorial Deadlines, Cleveland, Australia, v. 34. n. 4, p. 2-16, 2006.

CULL. M.; WHITTON, D. University studantes financial literacy levels: obstacles and Aids. Economic And Labour Relations Review, London, v. 22, n. 1, p. 100-114, 2011.

GREENSPAN, A. The importance of financial education today. Social Education, [s.1.], v. 69, n. 2, p. 64-67, Mar. 2005.

GRIFONI, A.; MESSY, F. A. Current status of National Strategies for Financial Education: a comparative analysis and relevant practices. OECD Working Papers on Finance, Insurance and Private Pensions, Paris, OECD Publishing, n. 16, Jun. 2012.

HAIR, J. F. et al. Análise multivariada de dados. 6. ed. Porto Alegre: Bookman, 2009.

HUNG, A.; PARKER, A. M.; YOONG, J., Defining and Measuring Financial Literacy. RAND Working Paper Series WR-708, Sept. 2009.

HUSTON, S. J. Measuring financial literacy. The Journal of Consumer Affairs, [s.l.], v. 44, n. 2, p. 296-316, Jun. 2010.

LUSARDI, A.; MITCHELL, O. S.; CURTO, V. Financial literacy among the young. Journal of Consumer Affairs, [s.1.], v. 44, n. 2, p. 358-380, Mar. 2010.

LUSARDI, A.; MITCHELL, O. S. Financial literacy and retirement planing in the United States. Journal of Pension Economics \& Finance, [s.1.], v. 10, n. 4, p. 509-525, Oct. 2011.

MAROCO, J. Análise estatística utilizando SPSS. 3. ed. Lisboa: Silabo, 2007. 
MILAN, M. V. G. O nível de alfabetização financeira de estudantes universitários: um estudo sobre a Fundação Escola de Comércio Álvares Penteado (FECAP). 2015. 75 f. Dissertação (Mestrado Profissional em Administração) - Fundação Escola de Comércio Álvares Penteado, São Paulo, 2015.

MUNDY, Shaun. Financial education programmes in schools: analysis of selected current programmes and literature - draft recommendations for best practices. OECD Journal: General Papers, v. 8, n. 3, a. 53 p. 1-66, 2009.

NORMAN, A. S. Importance of financial education in making informed decision on spending. Journal of Economics and International Finance, [s.l.], v. 2, n. 10, p. 199-207, Oct. 2010.

NORVILITIS, J. M.; MACLEAN, G. M. The role of parents in college students' financial behaviors and attitudes. Journal of Economic Psychology, University of the Munich, Germany, v. 31, n. 1, p. 55-63, 2010.

OPLETALOVÁ, A. Financial education and financial literacy in the Czech education system. Procedia - Social and Behavioral Sciences, Czech Republic, v. 171, p. 1176-1184, Jan. 2015.

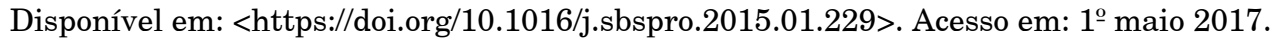

ORGANISATION FOR ECONOMIC CO-OPERATION AND DEVELOPMENT. Financial literacy and inclusion: results of OECD/INFE survey across countries and by gender. Paris, France: OECD Centre, 2013.

ORTON, L. Financial literacy: lessons from international experience. Canada: Canadian Policy Research Networks, Incorporated, 2007.

POTRICH, A. C. G.; VIEIRA, K. M.; KIRCH, G. Determinantes da alfabetização financeira: análise da influência de variáveis socioeconômicas e demográficas. Revista Contabilidade \& Finanças, São Paulo, v. 26, n. 69, p. 362-377, Dec. 2015. Disponível em: <http://www.scielo.br/ pdf/rcf/v26n69/1808-057x-rcf-26-69-00362.pdf>. Acesso em: 1ํ maio 2017.

POTRICH, A. C. G.; VIEIRA, K. M.; CERETTA, P. S. Nível de alfabetização financeira dos estudantes universitários: afinal, o que é relevante? Revista Eletrônica de Ciência Administrativa, Campo Largo, v. 12, n. 3, Nov. 2013. Disponível em: <https://doi.org/10.5329/RECADM.2013025>. Acesso em: $1^{\circ}$ maio 2017.

. Você é alfabetizado financeiramente? Descubra no termômetro de alfabetização financeira. In: ENCONTRO BRASILEIRO DE ECONOMIA E FINANÇAS COMPORTAMENTAIS, 2014, São Paulo. Anais... São Paulo, 2014. p. 1-24.

REMUND, D. L. Financial literacy explicated: the case for a clearer definition in na increasingly complex economic. The Journal of Consumer Affairs, [s.1.], v. 44, n. 2, p. 276-295, Jun. 2010. Disponível em: <https://doi.org/10.1111/j.1745-6606.2010.01169.x>. Acesso em: 1ํㅡaio 2017.

WILLIS, L. E. Against financial literacy education. Iowa Law Review, [s.l.], v. 94, n. 13, p. 197-285, Mar. 2008. Disponível em: <https://ssrn.com/abstract=1105384>. Acesso em: $1^{\text {o }}$ maio 2017. 